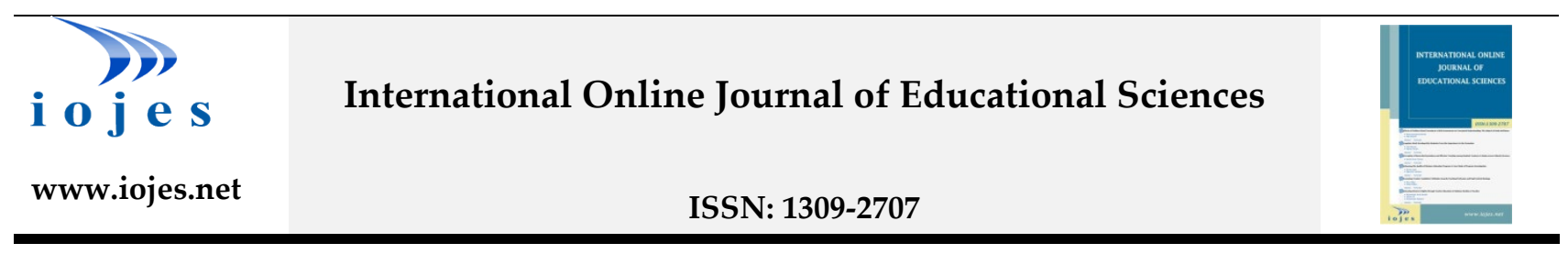

\title{
Prediction of Social Anxiety in Adolescence in the Context of Parental Attitudes and Emotion Regulation
}

\author{
Research Article \\ Lerzan YILMAZ ${ }^{1}$, Rojin YAZAR ${ }^{2}$, Ozlem TOLAN ${ }^{3}$ \\ ${ }^{1}$ Kocaeli Sağhlk ve Teknoloji Üniversitesi, Avrupa MYO, ORCID: 0000-0002-4238-5178 \\ ${ }^{2}$ Dicle University, Institute of Social Sciences, ORCID: 0000-0003-3888-1037 \\ ${ }^{3}$ Dicle University, Faculty of Literature, Department of Pyschology, ORCID: 0000-0002-8128-6498
}

To cite this article: Yilmaz, L., Yazar, R., \& Tolan, O. (2021). Prediction of social anxiety in adolescence in the context of parental attitudes and emotion regulation, International Online Journal of Educational Sciences, 13(4), 1198-1217.

\begin{tabular}{|c|c|}
\hline ARTICLE INFO & ABSTRACT \\
\hline Article History: & This study was conducted to examine the relationships between high school students' social anxiety \\
\hline \multirow{3}{*}{ Received: 19.03.2021 } & level and emotion regulation strategies and parental attitudes. 323 students studying at different \\
\hline & types of high schools in Diyarbakır in the 2019-2020 academic years participated in the present study \\
\hline & using the relational screening model. In the research, "Social Anxiety Scale for Adolescents", "Child \\
\hline Available online: & Rearing Attitudes Scale", "Adolescent Emotion Regulation Questionnaire (AERQ)" and a personal \\
\hline 15.09.2021 & information form prepared by the researcher were used. Descriptive statistics were explained in the \\
\hline & analysis of the data, and the Pearson product-moments correlation coefficient and hierarchical \\
\hline & regression analysis were used. According to the results, the model formed by the strict supervision / \\
\hline & control attitude of the parents and the internal dysfunctional emotion regulation strategies used by \\
\hline & adolescents predicts social anxiety, and the related variables can be risk factors for social anxiety in \\
\hline
\end{tabular}

(C) 2021 IOJES. All rights reserved

Keywords:

Adolescence, Social Anxiety, Emotion Regulation, Parental Attitudes

\section{Introduction}

For many people in daily life, communicating with others or being in environments where social skills are prominent might cause anxiety and fear. Most people are disturbed by social environments in which they assume they are watched or when they do not know the nature of the gaze directed at them, these people avoid such environments or tolerate this situation with intense distress (Furmark, 2002). In environments where there is social interaction, the possibility of a person being evaluated negatively by another may cause fear and anxiety. According to Teachman and Allen (2007), social anxiety is defined as feeling uncomfortable

${ }^{1}$ Corresponding author's address: Dicle University

Telephone: +905325488722

e-mail: ozlemtolan@gmail.com

DOI: https://doi.org/10.15345/iojes.2021.04.016 
being in areas with social interaction or being in conditions requiring performance. Feelings of avoiding this situation cause fear of being observed and evaluated by others. People with high social anxiety avoid social interaction areas because of the possibility of the person being rejected. People with social anxiety disorder may show some physical and emotional symptoms such as facial redness, sweating, tremors, heart palpitations, focusing problems, embarrassment, humiliation, and disapproval (Stein \& Stein, 2008). The fear of being stigmatized and ridiculed like a stupid person causes a decrease in the person's social skills with a high and harsh self-criticism; it can also lead to alienation from situations such as making friendships or expressing opinions in a group (Cox, Fleet \& Stein, 2004). It is accepted that social anxiety symptoms begin to occur in childhood, pre-adolescence, and late adolescence, when social interaction is considered intense and essential in the early stages (Rapee \& Spence, 2004; Chavira \& Stein 2005; Hofmann, Gutner \& Fang, 2012). It is stated that early social anxiety symptoms are among the factors that can cause a decrease in functionality and a decrease in life satisfaction in family, peer relationships, academic achievement, work and other social interaction environments (Aderka, Hofmann, Nickerson, Hermesh, Gilboa-Schechtman, Marom, 2012; Kessler, 2003). It is stated that social anxiety is felt more intensely in interaction with other people, in situations that require physical performance, and it occurs commonly during developmental period transitions or environmental changes (Schmidt, 2008). Social anxiety symptoms in early childhood are associated with shyness (Hayward et al., 2008; Tsui, Lahat \& Schmidt, 2016). It is known that shy boys have less trouble regulating negative emotions than girls who are shy (Theall-Honey \& Schmidt, 2006). Johnson and Glass (1989) stated in their study that boys with high social anxiety had more difficulties in their relationships with girls than boys with normal social anxiety in terms of social skills, attention-grabbing, and ability to continue their conversation. On the emergence of social anxiety disorder, there might be multiple factors influential such as genetic factors, the timid temperament of the person, cognitive distortions related to the situation, stressful life events, exposure to peer bullying, neglect experience, lack of social skills or knowledge, the effect of learning mechanisms, the society being an individualist or collectivist culture, parenting styles, attachment (Stein \& Stein, 2008; Wong \& Rapee, 2016). Social anxiety experienced during adolescence is considered as a normal situation considering the importance given to the social environment of the adolescent, and it is stated that the social anxiety disorder starts at the age of 13 (Kessler et al., 2005) and the age at which it is felt most intensively is 15 years (Teachman \& Allen, 2007; Kessler et al., 2012). In adolescence, when appearance is extremely important, the person's exposure to situations that may increase the level of social anxiety, may cause social anxiety to continue existing and increase its violence (Mash \& Wolfe, 2002). While the mother and father represent the authority in the child's life, they also have a primary and supportive role in terms of the child's survival and social cohesion. The lack of reassuring parent roles can cause the child to activate the defense mechanisms and think they are threatened while with others (Türkçapar, 1999). In the early childhood period, there is a child that the parent tries to shape and a parenting structure that is tried to be formed (Maccoby, 1980). Considering that parental attitudes affect the child's physical, social, cognitive development and language development (Erdogan \& Uçukoğlu, 2011), its importance becomes even more evident.

Baumrind (1996) discussed parental attitudes in three groups: authoritative/explanatory (authoritative), authoritarian and permissive. The authoritative family typology provides a democratic family environment. This environment does not damage the family's communication network and family relations due to different styles and opinions. Family can discuss different views and are not forced to agree on the same idea. After adolescence, when conflicts are more intense, family relationships can be restored, and it becomes easier and more moderate to meet at common points. Adolescents may experience conflicts with their parents from time to time, even while growing up in a democratic family environment. Still, when they give their parents emotional reactions, they react in a more balanced and controlled manner compared to adolescents who grow up in other family environments (Ersoy, 2013). Even if having a strict approach at times, the warm attitude of the parents helps the child fulfil reasonable and realistic expectations. It is known that parents who are 
sensitive to the child's interests and skills and who are role models feed the social adaptation of their children (Bandura, 1977). On the other hand, parents with authoritarian attitudes aim to create a disciplined environment with harder and stricter attitudes while raising their children. In an authoritarian parenting style, the child is always expected to obey and meet expectations while responding with strict discipline and a cold approach. Controls, strict rules, prohibitions, and punishments can cause fear, anxiety, and low self-esteem in the child (Weiss, Dodge, Bates \& Pettit, 1992; Chen, Dong \& Zhou, 1997). Parental attitude, in which parents' influence on children is not evident, and the boundaries are not drawn, is defined as permissive parental attitude. There is a profile of accepting and warm parents who have a wide range of flexibility in the permissive attitude, who avoid punishing their children, whose behaviours are approved. It is also known that parents have fewer expectations and are reasonable for the child (Maccoby \& Martin, 1983). Parenting styles were included in a study by Steinberg, Dornbusch and Brown (1992) with the dimensions of warmth, controlling and democracy according to adolescent development. Warmth is explained as being aware of the adolescent's emotional needs and responding to them. Control is explained by the way behaviours are supervised and shaped. Democracy is explained by respecting the feelings and thoughts of the adolescent and directing them to psychological autonomy. While warmth, control, and democracy can be seen at high levels in the authoritative parenting style, all three dimensions are seen at low levels in the uninvolved parenting style (Kerr, Stattin, \& Özdemir, 2012). Takako (1994) states that the parents of people with social anxiety have high control, being disciplined, overprotection and emotional neglect. Overprotective parental attitude can cause parents to treat their children as if they are babies in need of care. Parents who want to be with their children at all times can make them selfish, irresponsible and spoiled. According to Carothers and Parfitt (2017), these children with overprotective parents may experience not being able to make their own decisions and lagging in social skills. It is claimed that the problems experienced in the context of relationships with parents, peers, and romantic relationships during adolescence and various difficulties in school life lay the groundwork for anxiety disorders and depression (Lee et al., 2014; Young, Sandman \& Craske, 2019). With the adolescence period, changes occur in emotion regulation. Although there is a decrease in the sense of trust in parental support in emotion regulation, it is stated that problems may occur in internal functional emotion regulation strategies, and the use of dysfunctional strategies might decrease in the forthcoming periods (Zimmermann \& Iwanski, 2014).

One of the variables examined in the current research is the concept of emotion regulation. Hofman (2007) states that social phobia is associated with difficulties in emotion regulation. The dimension of emotion regulation, which starts with the first stages of life and continues throughout life, turns into a state that begins to be shaped according to the self with the adolescence period and is structured by cognitive skills (Compas et al., 2017). The emotion that occurs with situational premises or an event requiring attention that has an internal or external trigger is experienced as a result of the person's implicit or explicit evaluation of whether it serves the purpose or not and leads to the occurrence of situational behavior (Jazaieri et al., 2013). Emotion regulation has been conceptualized as a set of efforts related to how and in which situations the existing emotions or newly emerged emotions of the person are experienced and expressed (Gross, 1998). Emotion regulation enables people to be aware of the changes in the situation caused by themselves or externally, adapt, manage, and analyze the process, and make changes when necessary (Bridges, Denham \& Ganiban, 2004). The emotion regulation process, which is accepted as a pioneer on the individual's subjective well-being and functionality, is divided into two as functional or non-functional strategies within its context-specific context. If the emotion's type and intensity show a wrong course when it occurs, it can be in a confusing role and turn into a harmful state. The key role is to interpret emotions beneficially about the situation and develop the ability to cope with the situation. (Aldao \& Nolen-Hoeksema, 2012). Gross (1998) mentions two strategies in the emotion regulation process as "premise-focused" and "response-oriented". Prediction-oriented strategies (e.g., re-evaluation) are used before the emotion emerges or while it is just about to emerge. In contrast, 
response-oriented strategies (e.g., suppression of emotion expression) are used after the emotion has emerged. Although these strategies show that the emotion regulation strategy applied according to the target behavior is not functional or functional, they can be evaluated as positive or negative in terms of psychological health (Gross \& John, 2003). Suppose the emotion is appropriate to the context of the message given to the person and provides the process of accepting and sustaining the emotion. In that case, it turns into a target-oriented and functional strategy (Power \& Dalgleish, 1997). Otherwise, the person may tend to barricade with their emotions, suppress or reject their expression. This shows that a dysfunctional strategy was used. According to Nolen-Hoeksema and Aldao (2011), emotion regulation strategy, which is functional under normal conditions, may cease to be functional if it does not appear appropriate to the context (e.g., problem-solving strategy is a functional strategy when it is a solvable problem). In cases of social contact, the person can respond to stimuli in the outside world with cognitive, psychological or behavioral outputs while controlling potential stress factors with emotion regulation strategies (Garnefski, Kraaij \& Spinhoven 2001). It is known that stress factors controlled by functional or non-functional strategies also include internal and external emotion regulation strategies. Using personal, internal resources while emotion regulation is done is called internal strategies whereas using environmental and external resources are called external emotion regulation strategies (Phillips \& Power, 2007). While internal processes are at the forefront for adults, it is known that external strategies are mostly used in development processes (Gross \& Thompson, 2007; Calkins \& Hill, 2007).

According to Gross (2008), emotion regulation is related to one's emotions, the way one experiences emotions, the time it emerges and during the process of expressing the emotion. It is observed that dysfunctional strategies of emotion regulation are more prominent during and after adolescence. Inability to regulate negative emotions adequately can lead to the use of dysfunctional strategies and mental health problems (Gullone, Hughes, King \& Tonge, 2009). It is known that re-evaluation, which is among the compatible strategies of emotion regulation, is associated with more positive mental health benefits for adolescents (Bonanno, Papa, Lalande, Westphal, Coifman, 2004). The suppression strategy, which is among the dysfunctional strategies of emotion regulation, causes negative mental health effects as it does not allow emotion expression (Gullone \& Taffe, 2012). Inability to regulate emotions can increase adolescents' emotional and behavioral problems and their tendency to depression, aggression or substance abuse (Stein et al., 2006).

Many studies stated that people with high social anxiety levels define their parents as overprotective, apathetic, and rejecting (Hudson \& Rapee, 2000). Therefore, considering the social functions of perceived parental attitude and emotion regulation skills in adolescence regarding the bases of social anxiety, this study aims to examine the relations of social anxiety, parental attitudes and emotion regulation strategies. In line with this general purpose, the following questions were sought:

1. Is there a significant relationship between high school students' social anxiety levels, emotion regulation strategies and parental attitudes?

2. Do parental attitudes and emotion regulation strategies used by adolescents significantly predict the level of social anxiety in adolescents?

\section{Method}

\section{Research Model}

The research is designed in a relational screening model. The relational screening model aims to determine the presence and degree of co-change between two or more variables (Karasar, 2012). In this context, the study's main purpose is to examine the relationships between high school students' social anxiety levels, emotion regulation strategies, and parental attitudes. Students' social anxiety levels as predicted variable, emotion regulation strategies and parental attitudes were examined as predictor variables. 


\section{Study Group}

The current study was carried out with preparatory class, $9^{\text {th }}, 10^{\text {th }}, 11^{\text {th }}$, and $12^{\text {th }}$-grade students studying in 4 different high schools in Diyarbakır in the 2019-2020 academic year. The research universe is high school students living in Diyarbakır and studying at schools in Diyarbakır city centre districts in the 2019-2020 academic year. The study sample is 323 high school students. The schools where the scales are applied consist of schools that provide education in public and private schools and differ in terms of factors such as academic success levels and socio-economic characteristics of students. A total of 323 students, 181 females (56\%) and 142 males (44\%) participated in the study. The ages of the participants are between 14-19; the average age is 15.8. $66.3 \%$ of the students study in public school and $33.7 \%$ in private school. Individuals participating in the study were selected by a simple random sampling method, and volunteering was used for participation in the study.

\section{Data Collection Tools}

The data of the present study were collected using "Personal Information Form", "Social Anxiety Scale for Adolescents", "Child Rearing Attitudes Scale" and "Emotion Regulation Scale for Adolescents".

\section{Personal Information Form}

The Personal Information Form was created in order to obtain various demographic data about the students participating in the research. The related form includes questions about age, gender, grade level, and school type.

\section{Social Anxiety Scale for Adolescents}

The social anxiety scale for children was developed by LaGreca, Dandes, Wick, Shaw and Stone (1988) and the scale was adapted for adolescents by LaGreca and Lopez (1998). It contains three subscales: Fear of Negative Evaluation (FNE), Social Avoidance and Distress-New (SAD-New) and Social Avoidance and Distress-General (SAD-Gen). The adaptation study of the scale into Turkish was carried out by Aydın \& Tekinsav-Sütçü (2007). The Cronbach Alpha internal consistency of the scale was found to be .83 for the (FNE), .68 for the SAD-Gen, .71 for the SAD-New, and .88 for the whole scale. In the present study, the internal consistency for the whole scale was .82; The internal consistency of the sub-dimensions was determined as .79 for "fear of negative evaluation", .63 for "social avoidance and distress in general situations", and .64 for "social avoidance and distress in new situations".

\section{Child Rearing Attitudes Scale}

The Child-Rearing Attitudes Scale was developed by Maccoby and Martin (1983) as a result of the studies of Steinberg et al. (1992). The adaptation study of the scale into Turkish was done by Sümer and Güngör (1999). The Cronbach Alpha internal consistency coefficient for the mother subscale of the scale is .75, while the acceptance/care/affection sub-dimension Cronbach Alpha reliability coefficient is .90. The strict supervision/control sub-dimension of the scale was found to be .78. Father subscale explains $60.2 \%$ of the total variance and consists of five factors. The Cronbach Alpha internal consistency coefficient of the father subscale, made with 21 items, is .82. Cronbach Alpha reliability coefficients of acceptance / care / love and strict supervision / control sub-dimensions are .91 and .80 , respectively. In this study, the internal consistency coefficient was .72 for the whole mother subscale, .87 for the acceptance/care/affection sub-dimension, and .78 for the strict supervision/control sub-dimension. The internal consistency coefficient for the entire father subscale was $.80, .88$ for the acceptance/care/affection sub-dimension, and .83 for the strict supervision/control sub-dimension. 


\section{Adolescent Emotion Regulation Questionnaire (AERQ)}

Adolescent Emotion Regulation Questionnaire (AERQ) was developed by Phillips and Power (2007), and an adaptation study of the scale into Turkish was done by Duy and Yildiz (2014). Internal consistency reliability coefficients were .53 for the internal-functional emotion regulation sub-dimension, .56 for the external-dysfunctional emotion regulation sub-dimension, .36 for the internal dysfunctional emotion regulation sub-dimension, and .44 for the external-functional emotion regulation sub-dimension. In this study, the internal consistency coefficient for the whole of AERQ was .67; 80 for internal functional emotion regulation, .56 for external functional emotion regulation, .71 for internal dysfunctional emotion regulation, and .74 for external dysfunctional emotion regulation has been found.

\section{Data Analysis}

The analysis of the data obtained within the study's scope was made using the IBM SPSS-24 (Statistical Package for Social Sciences) package program. The data were first examined in terms of univariate and multivariate normality assumptions. For this purpose, the skewness - kurtosis values of the data were calculated within the scope of the univariate normality assumption. It has been determined that the relevant values are between -1.5 and +1.5 . In order to verify the normality assumptions, the kurtosis-skewness values of the data should be between -1.5 and +1.5 (Tabachnick \& Fidell, 2007). In this context, it is seen that the available research data show a normal distribution. In order to test multivariate normality assumptions, the Durbin-Watson coefficient and VIF values were calculated. Whether there is an autocorrelation problem among the study variables was tested by calculating the Durbin-Watson coefficient. The Durbin-Watson coefficient calculated for the study's independent variables, parental attitudes and emotion regulation strategies, and the dependent variable, social anxiety, was found to be $d=1.808$. The Durbin-Watson coefficient, which takes a value between 1.5-2.5, according to Kalayc1 (2008), indicates that there is no autocorrelation problem between the variables. The variance inflation factor (VIF) and tolerance values were examined to test the multicollinearity problem among the independent variables discussed in the study. VIF values for independent variables are between 1.10 and 1.64; It has been determined that the tolerance values are between 0.6 and 0.9 , the VIF value less than 10 and the tolerance values greater than 0.2 show that there is no multiple connection problem regarding the independent variables (Field, 2005). Thus, it is seen that the present study provides the necessary conditions for regression analysis. Pearson correlation coefficient was calculated to determine the relationships between variables. Hierarchical linear multiple regression analysis was used to determine the predictive power of emotion regulation skills and parental attitudes towards social anxiety.

\section{Findings}

In this section, the analysis results made to determine the relationship between the emotion regulation skills of adolescents and parental attitudes with their social anxiety levels are included. In Table 1, values showing descriptive statistics regarding the variables of the research are presented.

Table 1. Descriptive Statistics Regarding the Variables of the Study

\begin{tabular}{lccccccc}
\hline Variable & $N$ & Min & Max & $\bar{X}$ & $S d$ & Skewness & Kurtosis \\
\hline Fear of Negative Evaluation & 323 & 1.00 & 5.00 & 2.13 & .86100 & .945 & .697 \\
\hline Social Avoidance and Distress-General & 323 & 1.00 & 5.00 & 1.93 & .75015 & 1.112 & 1.379 \\
\hline Social Avoidance and Distress-New & 323 & 1.00 & 5.00 & 2.50 & .78303 & .372 & .062 \\
\end{tabular}




\begin{tabular}{lccccccc}
\hline $\begin{array}{l}\text { Mother } \\
\text { acceptance/care / affection }\end{array}$ & 323 & 1.00 & 5.00 & 3.72 & .80717 & -.725 & .134 \\
\hline Mother Strict supervision/control & 323 & 1.18 & 5.00 & 2.98 & .73736 & .062 & -.063 \\
\hline $\begin{array}{l}\text { Father } \\
\text { Acceptance/care/ affection }\end{array}$ & 323 & 1.00 & 5.00 & 3.44 & .87613 & -.389 & -.335 \\
\hline $\begin{array}{l}\text { Father strict supervision/control } \\
\text { Internal Functional Emotion Regulation }\end{array}$ & 323 & 1.00 & 5.00 & 2.89 & .82911 & .170 & -.265 \\
\hline $\begin{array}{l}\text { Internal Dysfunctional Emotion } \\
\text { Regulation }\end{array}$ & 323 & 1.00 & 5.00 & 2.94 & .91081 & .182 & -.751 \\
\hline $\begin{array}{l}\text { External Functional Emotion Regulation } \\
\text { External Dysfunctional Emotion }\end{array}$ & 323 & 1.00 & 5.00 & 2.99 & .88342 & -.103 & -.562 \\
\hline \begin{tabular}{l} 
Regulation \\
\hline
\end{tabular} & 323 & 1.00 & 5.00 & 2.25 & .87770 & .784 & -.365 \\
\hline
\end{tabular}

Table 2. The Relationships Between Students' Social Anxiety Levels, Emotion Regulation Strategies and Parental Attitudes

\begin{tabular}{|c|c|c|c|c|c|c|c|c|c|c|c|}
\hline Variables & 1 & 2 & 3 & 4 & 5 & 6 & 7 & 8 & 9 & 10 & 11 \\
\hline \multicolumn{12}{|l|}{ 1. Fear of } \\
\hline Negative & 1 & & & & & & & & & & \\
\hline \multicolumn{12}{|l|}{ Evaluation } \\
\hline \multicolumn{12}{|l|}{ 2. Social } \\
\hline \multicolumn{12}{|l|}{ Avoidance } \\
\hline and & $.591^{* *}$ & 1 & & & & & & & & & \\
\hline \multicolumn{12}{|l|}{ Distress- } \\
\hline \multicolumn{12}{|l|}{ General } \\
\hline \multicolumn{12}{|l|}{ 3. Social } \\
\hline \multicolumn{12}{|l|}{ Avoidance } \\
\hline and & $.568^{* *}$ & $.537^{* *}$ & 1 & & & & & & & & \\
\hline \multicolumn{12}{|l|}{ Distress- } \\
\hline \multicolumn{12}{|l|}{ New } \\
\hline \multicolumn{12}{|l|}{ 4. Mother } \\
\hline $\begin{array}{l}\text { acceptance/c } \\
\text { are / }\end{array}$ & -.096 & $-.132^{*}$ & -.079 & 1 & & & & & & & \\
\hline \multicolumn{12}{|l|}{ affection } \\
\hline \multicolumn{12}{|l|}{ 5.Mother } \\
\hline $\begin{array}{l}\text { strict } \\
\text { supervision/ } \\
\text { control }\end{array}$ & $.177^{* *}$ & $.156^{* *}$ & $.192^{* *}$ & $-.162^{* *}$ & 1 & & & & & & \\
\hline 6.Father & & & & & & & & & & & \\
\hline $\begin{array}{l}\text { acceptance/ } \\
\text { care/affectio } \\
\text { n }\end{array}$ & $-.167^{* *}$ & $-.192^{* *}$ & $-.138^{*}$ & $.464^{* *}$ & -.035 & 1 & & & & & \\
\hline
\end{tabular}


7.Father

strict

supervision/

$.170^{* *} \quad .117^{* *} \quad .128^{*}$

$\begin{array}{lll}.075 & .547^{* *} \quad-.053\end{array}$

1

control

8. Internal

Functional

Emotion

$-.072$

$.259^{* *}$

$.187^{* *}$

$.154^{* *}$

.107

1

Regulation

9. Internal

dysfunction

al Emotion

$.328^{*}$

$-.278^{* *}$

$.376^{* *}$

$-.296^{* *}$

$.146^{* *}$

.031

1

Regulation

10. External

Functional

Emotion

$-.018$

$-.029$

$-.078$

$.337^{* *}$

.045

$289^{* *}$

.015

Regulation

11. External

dysfunction

al Emotion

.075

$-.017$

$-.044$

$-.090$

$.137^{*}$

$-.046$

.104

$-.155^{* *}$

$.331^{* *}$

.027

1

Regulation

Note: ${ }^{*} p<.05 ;{ }^{* *} p<.01$

Considering the Pearson correlation coefficients related to the fear of negative evaluation, which is one of the sub-dimensions of social anxiety, in Table 2, the fear of negative evaluation and the strict supervision / control attitude of the mother $(\mathrm{r}=.177 ; \mathrm{p}<.01)$, the strict supervision / control attitude of the father $(\mathrm{r}=.170 ; \mathrm{p}$ $<.01)$ and internal dysfunctional emotion regulation $(\mathrm{r}=.328 ; \mathrm{p}<.01)$ have positive correlation; and there is a negative correlation between father acceptance / care / affection attitude $(r=-.167 ; p<.01)$. There is a significant negative correlation between social avoidance and distress and mother acceptance / care / affection attitude ( $\mathrm{r}$ $=-.132 ; \mathrm{p}<.05)$ and father acceptance / care / affection attitude $(\mathrm{r}=-.192 ; \mathrm{p}<$.$) . However, there is a positive$ correlation between social avoidance and distress in general situations and the strict supervision / control attitude of the mother $(\mathrm{r}=.156 ; \mathrm{p}<.01)$ and the strict supervision / control attitude of the father $(\mathrm{r}=.117 ; \mathrm{p}<.01)$. In addition, there is a positive significant relationship between social avoidance and distress and internal dysfunctional emotion regulation $(r=.284 ; \mathrm{p}<.01)$ in general situations.

It is observed that there is a negative correlation between social avoidance and distress in new situations, which is the sub dimension of social anxiety and father acceptance/care/affection $(r=-.138 ; \mathrm{p}<.05)$. It is seen that there is a positive correlation between social avoidance and distress in new situations, mother strict supervision/control attitude $(\mathrm{r}=.192 ; \mathrm{p}<.01)$, father strict supervision/control attitude $(\mathrm{r}=.128 ; \mathrm{p}<.01)$ and internal dysfunctional emotion regulation $(\mathrm{r}=.276 ; \mathrm{p}<.01)$.

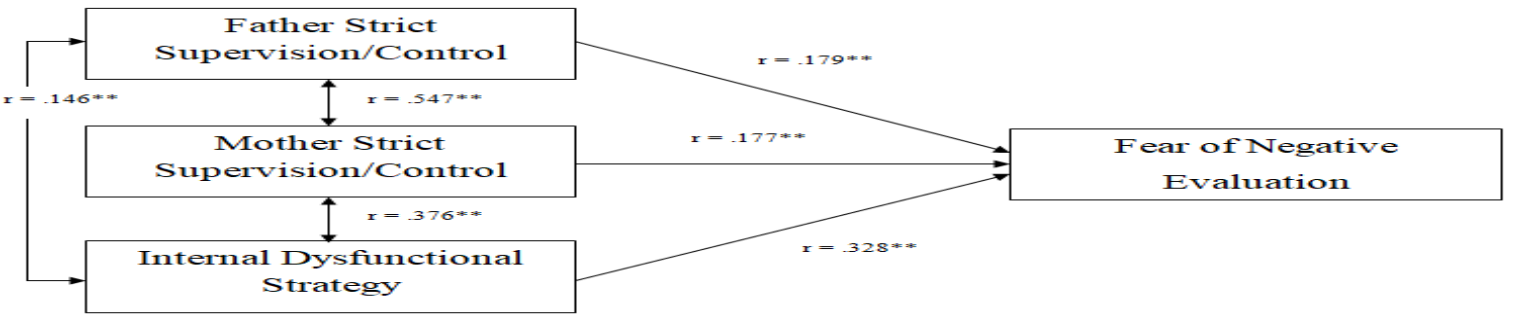


Figure 1. The model obtained on the relationship between fear of negative evaluation and father strict supervision / control, mother strict supervision / control, and internal dysfunctional strategy

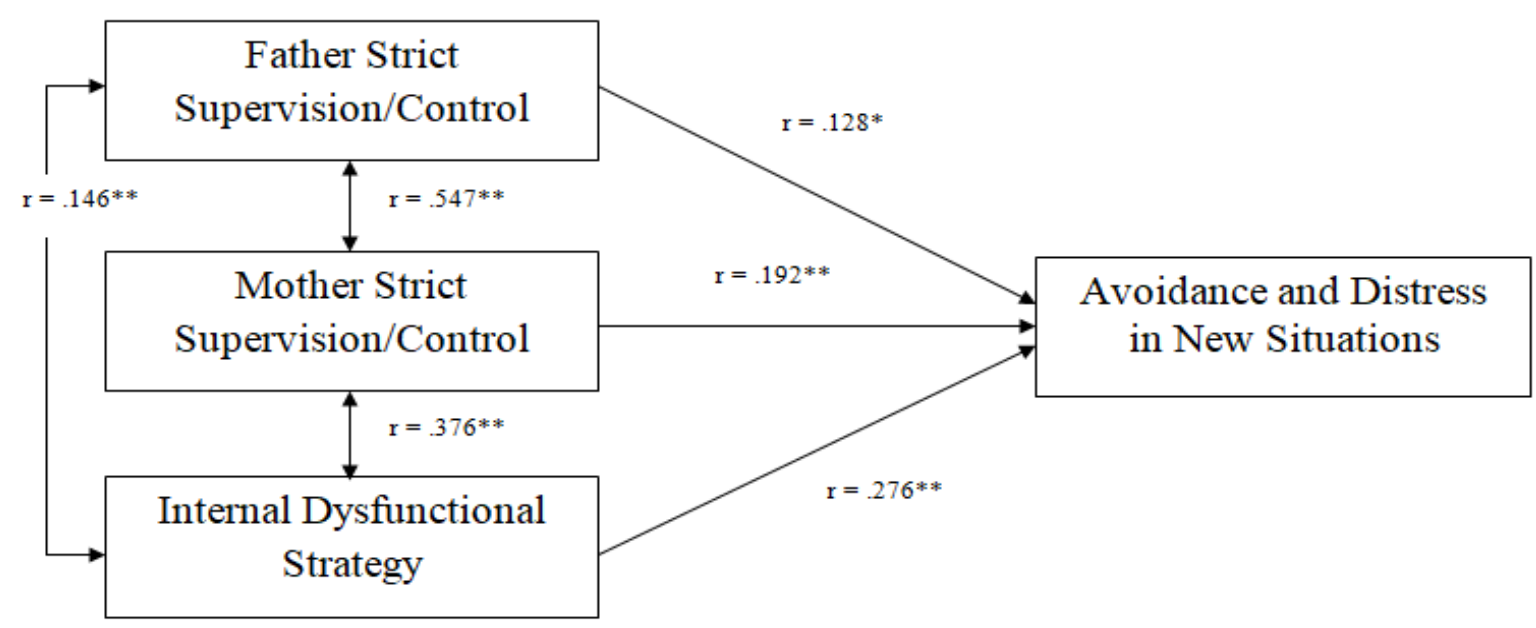

Figure 2. The model obtained on the relationship between social avoidance and distress in new situations and father strict supervision / control, mother strict supervision / control, and internal dysfunctional strategy

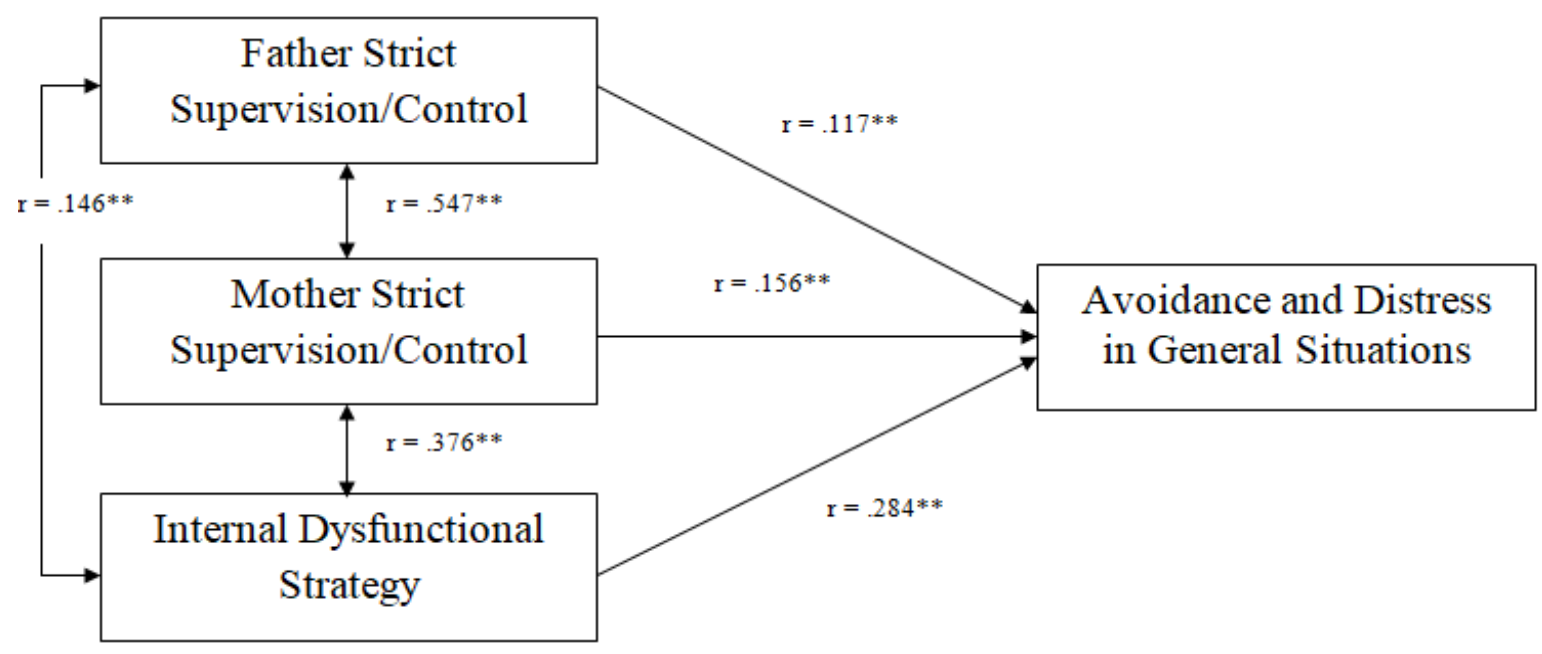

Figure 3. The model obtained on the relationship between social avoidance and distress in general situations and father strict supervision / control, mother strict supervision / control and internal dysfunctional strategies

Table 3. Hierarchical Regression Analysis Results depicting Prediction of Social Avoidance and Distress in General Situations, regarding Students' Emotion Regulation Strategies and Parental Attitudes

\begin{tabular}{ccccccc}
\hline Model & $\boldsymbol{R}$ & $\boldsymbol{R}^{\mathbf{2}}$ & $\boldsymbol{R}^{2}$ (Adj) & Std.Err. & $\boldsymbol{F}$ & $\boldsymbol{P}$ \\
\hline FSSC & .117 & .014 & .011 & .74619 & 4.426 & .036 \\
FSSC/ & .160 & .026 & .020 & .74277 & 4.216 & .016 \\
MSSC & & & & & & \\
$\begin{array}{l}\text { FSSC/ } \\
\text { MSSCl } \\
\text { IDERS }\end{array}$ & .295 & .087 & .078 & .72024 & 10.099 & .000 \\
\hline
\end{tabular}


FSSC: Father Strict Supervision / Control

MSSC: Mother Strict Supervision / Control

IDERS: Internal Dysfunctional Emotion Regulation strategies

Dependent Variable: Social Avoidance and Distress in General Situations

When Table 3 is examined, it is determined that in the first model, strict supervision / control attitude of the father significantly predicts the level of social avoidance and distress in general situations $(\mathrm{p}<.05)$ and explains the total variance by $1.4 \%$. The mother strict supervision / control attitude added to the model in the second step contributed significantly to the model $(\mathrm{p}<.05)$ and explained the total variance by $2.6 \%$. In the third and last step, when the internal dysfunctional emotion regulation strategy was added to the model, it was determined that the model was significant $(\mathrm{p}<.05)$ and explained the total variance by $8.7 \%$.

Table 4. Hierarchical Regression Analysis Results Depicting the Prediction of Social Avoidance and Distress in New Situations, Sub-Dimensions of Social Anxiety, regarding Students' Emotion Regulation Strategies and Parental Attitudes

\begin{tabular}{ccccccc}
\hline Model & $\boldsymbol{R}$ & $\boldsymbol{R}^{2}$ & $\boldsymbol{R}^{2}$ (Adj) & Std.Err. & $\boldsymbol{F}$ & $\boldsymbol{P}$ \\
\hline FSSC & .128 & .016 & .013 & .77780 & 5.344 & .021 \\
FSSCl & .194 & .037 & .031 & .77063 & 6.226 & .002 \\
MSSC & & & & & & \\
FSSCl & .087 & .079 & .75157 & 10.175 & .000 \\
$\begin{array}{l}\text { MSSCl } \\
\text { IDERS }\end{array}$ & .296 &. & & & \\
\hline
\end{tabular}

FSSC: Father Strict Supervision / Control

MSSC: Mother Strict Supervision / Control

IDERS: Internal Dysfunctional Emotion Regulation strategies

Dependent Variable: Social Avoidance and Distress in New Situations

As seen in Table 4, in the first model, it was determined that the strict supervision/control attitude of the father significantly predicted the level of social avoidance and anxiety in new situations $(p<.05)$ and explained the total variance by $1.6 \%$. In the second step, the mother, strict supervision / control attitude, added to the model contributed significantly to the model $(\mathrm{p}<.05)$ and explained the total variance by $3.7 \%$. In the last step, by adding the internal dysfunctional emotion regulation strategy to the model, it was determined that the model was significant $(\mathrm{p}<.05)$ and explained the total variance by $8.7 \%$.

Table 5. Hierarchical Regression Analysis Results Regarding the Prediction of Negative Evaluation Dimension, One of the Sub-Dimensions of Social Anxiety, by Students' Emotion Regulation Strategies and Parental Attitudes

\begin{tabular}{ccccccc}
\hline Model & $\boldsymbol{R}$ & $\boldsymbol{R}^{2}$ & $\boldsymbol{R}^{2}$ (Adj) & Std.Err. & $\boldsymbol{F}$ & $\boldsymbol{P}$ \\
\hline FSSC & .170 & .029 & .026 & .84980 & 9.544 & .002 \\
FSSC/ & .198 & .039 & .033 & .84667 & 6.496 & .002 \\
MSSC & & & & & & \\
FSSCl & & & & & & \\
MSSCl & .350 & .123 & .115 & .81019 & 14.885 & .000 \\
IDERS & & & & & & \\
\hline
\end{tabular}


FSSC: Father Strict Supervision / Control

MSSC: Mother Strict Supervision / Control

IDERS: Internal Dysfunctional Emotion Regulation strategies

Dependent Variable: Fear of Negative Evaluation

When Table 5 is examined, it is determined that in the first model, strict supervision / control attitude of the father significantly predicts the fear of being evaluated negatively $(\mathrm{p}<.05)$ and explains the total variance by $2.9 \%$. In the second step, mother strict supervision / control attitude was added to the model. It is determined that the model is significant $(\mathrm{p}<.05)$ and explains the total variance by $3.9 \%$. With the internal dysfunctional emotion regulation strategy added to the model in the third and last step, it is seen that the model is significant $(\mathrm{p}<.05)$ and explains the total variance by $12.3 \%$.

\section{Discussion, Conclusion and Recommendations}

The present study aimed to examine the relationships between high school students' social anxiety level and parental attitudes and emotion regulation strategies. According to the research results, it was concluded that there is a relationship between social anxiety, child-rearing attitudes and emotion regulation strategies. The first finding obtained within the study's scope is that between the fear of negative evaluation, which is one of the sub-dimensions of social anxiety, and the father's accepting, caring and loving attitude; There is a positive and significant relationship between parent strict supervision and control attitude. The findings of the study are similar to the studies in the related literature. In a study conducted by Chen, Liu and Li (2000) with a group of children from 12 to 14 years of age, it was concluded that fathers' warm and tolerant attitudes significantly predicted children's social adaptation and academic success. In an accepting, caring, and loving family environment, the children who are old enough to take care of themselves and their parents continue to spend time and share together, allowing the child to maintain functionality and emotional ties in the family despite his advanced age (Kağıtçıbaşı, 1982). When the current research results are considered, it is found that in a relationship where the parents offer acceptance, care and love, the adolescent develops higher self-esteem and less fear of negative evaluation. From another point of view, when the related literature is examined, it is observed that the lack of social skills and the need for external control increase in adolescents who are brought up with a pronounced parental control; It is suggested that this situation is also related to the fear of negative evaluation (Lieb et. al., 2000; Rubin, Cheah \& Fox, 2001; Coplan, Prakash, O’Neil, \& Armer 2004; Cankardaş, 2019). It is discussed that the family environment, which is the starting point of social relations, giving the adolescent personal space, being away from judgmental attitude and rather having supportive attitude, is an essential factor in the individual's self-expression. It is thought that the adolescent's concerns that his feelings and thoughts will be evaluated negatively through being judged, criticized and supervised have increased. In the study conducted by Allaman, Joyce and Crandall (1972), it is stated that children who are raised with a strict parenting style experience more intense approval anxiety. Similarly, in a study conducted by KoydemirÖzden and Demir (2009), it was determined that the fear of negative evaluation mediates the relationship between the harsh and controlling attitudes of the parents and the fear of rejection and shyness. It is stated that children who grow up in family environments where the democratic parental attitude is dominant, which is known as the opposite of strict and authoritarian parental attitude, are able to express their opinions better and have less fear of rejection (Kelley, Brownell, \& Campbell, 2000). Considered in this context, it is thought that the adolescent experiences the fear of negative evaluation, which manifests itself with symptoms such as anxiety of being approved and criticized, and difficulty in expressing himself in interpersonal and social relations, in the face of the strict and strict controlling attitude of the parents.

According to another result obtained from the present study, social avoidance and distress in general situations are negatively affected by the parents' accepting interest and love attitude; and positively affected 
by Parents' strict supervision attitude. The strict disciplinary practices of their parents and their attitude towards low emotional support increase individuals' social anxiety symptoms (Takako, 1994; Hudson \& Rapee, 2000). In this context, it is evaluated that avoiding social situations and feeling distress is related to parental control and restrictions. It is thought that adolescents who grow up under supervision and pressure generally experience a general avoidance in social situations, with the generalization that concerns such as approval and criticism developing in the family can be seen in other social relationships.

Social anxiety avoiding new situations and discomfort dimensions were negatively affected by the father's accepting, caring and loving attitude; It is observed that there is a positive relationship between the strict supervision and control attitude of the mother and father. It is known that the physical, cognitive and emotional changes experienced during adolescence are new and challenging and affect the relationship the adolescent establishes with his social environment. In this context, the concept of "imaginary audience" emerges as an essential factor. The imaginary spectator, which is seen in adolescents and expresses his belief that his environment is watching the adolescent, is defined as the adolescent who has directed the focus of attention to himself, the adolescent who is constantly watching him, interested in his behavior, observing his appearance always, and presenting his performance to the audience in his mind (Elkind, 1967. Galanaki, 2012). Considering that ego development during adolescence is shaped in the context of egocentrism (Elkind, 1967), it is stated that the adolescent tends to maintain his social and interpersonal relationships with the belief of "imaginary follower" (Lapsley, 1993; Frankenberger, 2000). In this context, it is considered that the adolescent's behavior of avoiding new situations in social environments increases when being watched frequently by his / her parents who have a strict supervision and controlling attitude and having the anxiety of being criticized is combined with the imaginary audience belief.

According to another result obtained from the present study, there is a positive relationship between internal dysfunctional emotion regulation and social anxiety sub-dimensions. This finding overlaps with many studies in the relevant literature (Kashdan \& Breen, 2008; McLean, Miller \& Hope, 2007; Perini, Abbott \& Rapee, 2006; Brozovich \& Heimberg, 2008). One of the internal dysfunctional emotion regulation strategies, suppression, manifests itself as inhibition of emotion expression. Ignoring or avoiding one's emotions or focusing on negative thoughts repeatedly refer to dysfunctional emotion regulation strategies. In a study conducted by Sackl-Pammer et al. (2019), it is stated that adolescents with high social anxiety levels use suppression and rumination, among dysfunctional emotion regulation strategies, more than adolescents with low social anxiety levels. Considering the results obtained in the present study, it is evaluated that social anxiety level increases as the adolescent uses strategies that lead to negative emotions such as suppression and avoidance rather than re-evaluation, interpretation, and problem-solving face of a situation. Similar to the research results, it is observed that there is a negative relationship between the intense use of dysfunctional emotion regulation strategies such as suppression and avoidance and social anxiety symptoms (Aldao, NolenHoeksema, \& Schweizer 2010; Aldao, Jazaieri, Goldin, \& Gross, 2014).

In the present study, it was concluded that the strict supervision-control attitude of the father, the strict supervision-control attitude of the mother, and the internal dysfunctional emotion regulation strategies together significantly predicted the sub-dimensions of social anxiety. The model created in the regression analysis shows that the mother's strict supervision-control attitude is more powerful than the father's strict supervision-control attitude to predict social anxiety in adolescents. However, the related model shows that if the mothers of the adolescents who were raised with the strict supervision-control attitude of the father have a similar strict supervision and control attitude, the level of social anxiety in adolescents is explained at a higher rate. There are studies showing that the mother's strict supervision and control attitude is a predictor of social anxiety in adolescents (Akyıl, 2000; Festa \& Ginsburg, 2011; Rork \& Morris, 2009). Parental control prevents the child from discovering new environments and the development of coping skills with the 
problems he/she encounters and causes him to be more anxious (Barlow, 2002). Bögels and BrechmanToussaint (2006) states that parents' negligent and intrusive attitudes cause inhibition of emotional expression and an increase in social anxiety levels of adolescents. Considering the relevant results, in one of the studies conducted in our country (Sümer \& Güngör, 1999), when the acceptance/care and strict supervision/control dimensions for mothers and fathers were considered, it was observed that fathers were considered to be more supervising and controlling parents than mothers. Similarly, it is observed that fathers stay behind mothers in showing affection and care, and adolescents perceive them as a parent who punishes and supervises more (Yörükoğlu, 1992). In another study examining the relationship between parental attitudes and social anxiety, it was emphasized that fathers set less limits on their children than mothers; they tend to control less and offer more freedom to children (Bögels \& Phares, 2008). In addition, high anxiety levels of parents cause them to develop an overprotective attitude, which causes an increase in children's anxiety levels (Woodruff-Borden, 2002; Van der Bruggen, Stams, \& Bögels, 2008). When our country's traditional family structure is considered, the relationship between father and child is considered to be more distant than the mother. However, mothers are less involved in business life, taking a more active role in raising children than fathers, enabling mothers to spend more time with their children. It is thought that the intimacy of the relationship between the mother and the adolescent and the attitude of the parents are the factors that determine the social anxiety level of the adolescent. In this context, the fact that adolescents spend more time with their mothers than their fathers enable them to receive more feedback from their mothers on issues such as school, social life, and friendship relations. Considering the related findings, it is possible to say that the autonomous behavior potential of adolescents who are faced with a similar attitude of the mother in cases where the father's strict control and control attitude is dominant may be damaged. However, it is thought that the adolescent who experiences emotions such as being controlled and criticized very frequently may be using avoidance as a defense mechanism. Thus, the behavior of avoiding meeting with other people in social settings and the fear of being evaluated negatively arises. It is thought that adolescents who grow up with a strict control and control attitude may have an increased level of self-defect or inadequate perception and social anxiety symptoms. However, in the last step of the model created within the scope of regression analysis, it was found that the use of internal dysfunctional emotion regulation strategies together with the strict control and control attitude of the father and mother predicted the level of social anxiety at a higher level. Each-individual uses some emotion regulation strategies that may differ according to the situation or emotional reactions to regulate his emotions in the face of various situations (Gross, 1998). Cole, Michel, and O'Donnell (1994) stated that functional emotion regulation strategies enable the individual to behave more flexibly in the face of new experiences and situations gained in social environments (p.76). However, emotion regulation turns into internal functions with the advancing age and serves psychosocial development; many studies are showing that dysfunctional emotion regulation strategies or emotion regulation difficulties are associated with depression and anxiety (Turk, Heimberg, Luterek, Mennin, \& Fresco, 2005; McLaughlin, Hatzenbuehler \& Hilt 2009; Compas et al., 2017; Schafer, Naumann, Holmes, Tuschen-Caffier \& Samson, 2017). Although it is difficult for adolescents with high social anxiety to be in a social environment, the feeling of inadequacy they feel causes a significant emotional burden and enables them to live in a self-focused manner (Clark \& McManus 2002). Studies are showing that dysfunctional emotion regulation strategies such as suppression and avoidance are associated with anxiety (Aldao, Nolen-Hoeksema, \& Schweizer, 2010; Kring \& Sloan, 2010). Similarly, it is known that individuals with high social anxiety levels prefer to avoid environments and situations where negative emotions may arise (Jazaieri, Morrison, Goldin, \& Gross, 2015). Within the framework of the current research findings, it is thought that the increase in social anxiety levels, as well as the fact that the emotion regulation strategies used by adolescents who grow up with strict supervision and control attitude in the face of a negative situation, consist of dysfunctional strategies such as suppression and avoidance, may be caused by various factors. Adolescents who were raised with parental attitudes such as being supervised and criticized had low autonomy, low self-esteem, and negative self-perceptions and the 
inability to express their emotional and social experiences. With the use of dysfunctional emotion regulation strategies such as avoiding and suppression, their social anxiety levels also increased. However, in addition to the intense criticism, supervision, and frustration attitudes from their parents, it is evaluated that the adolescent's use of internal dysfunctional emotion regulation strategies more intensely causes him to avoid seeking social support and to avoid experiencing negative attitudes that he frequently encounters in the family environment. When the results obtained from the present study are considered in this context, it is concluded that adolescents who grow up with strict supervision and control attitudes of parents resort to internal dysfunctional emotion regulation strategies more frequently, causing high social anxiety, the adolescent's fear of being negatively evaluated more frequently and avoiding social situations.

The importance of parental attitude and emotion regulation strategies, which are among the variables that may be related to adolescents' social anxiety level, came to the fore again with this study. It is thought that psychoeducational studies on social anxiety and functional emotion regulation strategies are necessary for adolescents who continue their education in secondary schools \& high schools and their parents. The sample of this study is limited to some high schools in Diyarbakır. It is thought that studies to be conducted with more comprehensive and different samples may provide more extensive and clearer findings for the literature on the relevant subject. 


\section{REFERENCES}

Aderka, I. M., Hofmann, S. G., Nickerson, A., Hermesh, H., Gilboa-Schechtman, E., \& Marom, S. (2012). Functional impairment in social anxiety disorder. Journal of Anxiety Disorders, 26, 393-400.

Akyıl, Y. (2000). Percieved parental child-rearing practices and social anxiety in Turkish adolescents. (Master's thesis). Boğaziçi Üniversity, Istanbul, Turkey.

Aldao, A., Nolen-Hoeksema, S., \& Schweizer, S. (2010). Emotion-regulation strategies across psychopathology: A meta-analytic review. Clinical Psychology Review, 30, 217-237. doi:10.1016/j.cpr.2009

Aldao, A., \& Nolen-Hoeksema, S. (2012). When are adaptive strategies most predictive of psychopathology? Journal of Abnormal Psychology, 121(1), 276-281. doi:10.1037/a0023598

Aldao, A., Jazaieri, H., Goldin, P. R., \& Gross, J. J. (2014). Adaptive and maladaptive emotion regulation strategies: Interactive effects during CBT for social anxiety disorder. Journal of Anxiety Disorders, 28(4), 382-389.

Allaman, J. D., Joyce, C. S., \& Crandall, V. C. (1972). The antecedents of social desirability response tendencies of children and young adults. Child Development, 1135-1160.

Aydın, A., \& Tekinsav-Sütcü, S. (2007). Ergenler için sosyal kaygı ölçeğinin (ESKÖ) geçerlik ve güvenirliğinin incelenmesi. Çocuk ve Gençlik Ruh Sağı̆ğı Dergisi, 14 (2), 79-89.

Bandura, A. (1977). Self-efficacy: toward a unifying theory of behavioral change. Psychological Review, 84(2), 191.

Barlow, D. H. (2002). Anxiety and its disorders: The nature and treatment of anxiety and panic (2nd edn). New York: Guilford Press.

Baumrind, D. (1996). The discipline controversy revisited. Family Relations, 45(4), 405- 415.

Bögels, S., \& Phares, V. (2008). Fathers role in the etiology, prevention and treatment of child anxiety: A review and new model. Clinical Psychology Review, 28(4), 539-558.

Bögels, S. M., \& Brechman-Toussaint, M. L. (2006). Family issues in child anxiety: Attachment, family functioning, parental rearing and beliefs. Clinical Psychology Review, 26, 834-856.

Bonanno, G. A., Papa, A., Lalande, K., Westphal, M., \& Coifman, K. (2004) The importance of being flexible: The ability to both enhance and suppress emotional expression predicts long-term adjustment. Psychological Science, 15:482-487.

Bridges L. Denham, J., \& Ganiban, J. M. (2004) Definitional issues in emotion regulation research. Child Development, 75(2), 340-345.

Brozovich, F., \& Heimberg, R. G. (2008). An analysis of post-event processing in social anxiety disorder. Clinical Psychology Review, 28, 891-903. doi:10.1016/j.cpr.2008.01.002

Calkins, S. D., \& Hill, A. (2007). Caregiver Influence on Emerging Emotion Regulation: Biological and Environmental Transactions in Early Development. In: Gross, J.J., Ed., Handbook of Emotion Regulation, Guilford Press, New York, 229-248.

Cankardaş, S. (2019). Kadın ve Erkeklerde Olumsuz Değerlendirilme Korkusunun Belirlenmesinde Algılanan Ebeveyn Tutumları ve Benlik Saygısının Rolü. Psikoloji Çalışmaları, 39(1), 79-97.

Carothers, D., \& Parfitt, C. (2017). Disability or language difference: how do we decide? American Journal of Qualitative Research, 1(1), 1-12. 
Chavira, D. A., \& Stein, M. B. (2005). Childhood social anxiety disorder: from understanding to treatment. Child and Adolescent Psychiatric Clinics, 14(4), 797-818.

Chen, X., Dong, Q., \& Zhou, H. (1997). Authoritative and Authoritarian Parenting Practices and Social and School Performance in Chinese Children. International Journal of Behavioral Development, 21(4), 855-873. doi:10.1080/016502597384703

Chen, X., Liu, M., \& Li, D. (2000). Parental warmth, control, and indulgence and their relations to adjustment in Chinese children: A longitudinal study. Journal of Family Psychology, 14, 401-419.

Clark, D. M., \& McManus, F. (2002). Information processing in social phobia. Biological Psychiatry, 51, 92-100.

Cole, P. M, Michel, M. K., \& Teti, L. O. (1994). The development of emotion regulation and dysregulation: A clinical perspective. Monographs of the Society for Research in Child Development, 59 (2-3), 73-100.

Compas, B., Jaser, S., Bettis, A., Watson, K., Gruhn, M., Dunbar, J., \& Thigpen, J. (2017). Coping, emotion regulation, and psychopathology in childhood and adolescence: A meta-analysis and narrative review. Psychological Bulletin, 143, 939-991. doi:10.1037/bul0000110

Coplan, R. J., Prakash K, O'Neil, K., \& Armer M. 2004. Do you "want" to play? Distinguishing between conflicted-shyness and social disinterest in early childhood. Developmental Psychology, 40, 244-58.

Cox, B. J., Fleet, C., \& Stein, M. B. (2004). Self-criticism and social phobia in the US National Comorbidity Survey. Journal of Affective Disorders, 82, 227-34.

Duy, B., \& Yıldız, M. A. (2014). Ergenler için Duygu Düzenleme Ölçeğinin Türkçeye uyarlanması. Türk Psikolojik Danışma ve Rehberlik Dergisi, 5, 23-35.

Elkind, D. (1967). Egocentrism in adolescence. Child Development, 38(4), 1025-1034.

Erdoğan, Ö., \& Uçukoğlu, H. (2011). İlköğretim okulu öğrencilerin anne-baba tutumu algıları ile atılganlık ve olumsuz değerlendirilmekten korkma düzeyleri arasındaki ilişkiler. Kastamonu Ĕ̆itim Dergisi, 19(1), $51-72$.

Ersoy, E. (2013). Ortaokul öğrencilerinin algıladıkları anne baba tutumlari ile benlik saygisi ve depresyon düzeyi arasındaki ilişkinin incelenmesi. (Master's thesis). Fatih Üniversitesi, İstanbul, Turkey.

Festa, C. C., \& Ginsburg, G. S. (2011). Parental and peer predictors of social anxiety in youth. Child Psychiatry $\mathcal{E}$ Human Development, 42(3), 291-306.

Field, A. P. (2005). Is the meta-analysis of correlation coefficients accurate when population correlations vary? Psychological methods, 10(4), 444.

Fox, N., \& Calkins, S.D. (2003) The development of self-control of emotion: Intrinsic and extrinsic influences. Motivation and Emotion, 27, 7-26.

Frankenberger, K. D. (2000). Adolescent egocentrism: A comparison among adolescents and adults. Journal of Adolescence, 23(3), 343-354. doi:10.1006/jado.2000.0319

Furmark, T. (2002). Social phobia: overview of community surveys. Acta Psychiatrica Scandinavica, 105(2), 8493. doi:10.1034/j.1600-0447.2002.1r103.x

Galanaki, E. P. (2012). The imaginary audience and the personal fable: A test of Elkind's theory of adolescent egocentrism. Psychology, 3(6), 457-466.

Garnefskyi N., Kraaij, V., \& Spinhoven, P. H. (2001) Negative life events, cognitive emotion regulation and depression. Personality and Individual Differences, 30, 1311-1327. 
Gross, J. J. (1998). The emerging field of emotion regulation: An integrative review. Review of General Psychology, 2(3), 271-299.

Gross, J. J. (2008). Emotion regulation. Handbook of Emotions, 3(3), 497-513.

Gross, J. J., \& Thompson, R. A. (2007). Emotion Regulation: Conceptual Foundations. In J. J. Gross (Ed.), Handbook of Emotion Regulation (p. 3-24). The Guilford Press.

Gross, J. J., \& John, O.P. (2003) Individual differences in two emotion regulation processes: implications for affect, relationships, and well-being. Journal of Personality and Social Psychology, 85, 348-362.

Gross, J. J. (2002) Emotion regulation: Affective, cognitive, and social consequences. Psychophysiology, 39(3), 281-291. doi:10.1017/s0048577201393198

Gullone, E., \& Taffe, J. (2012). The Emotion Regulation Questionnaire for Children and Adolescents (ERQCA): A psychometric evaluation. Psychological Assessment, 24(2), 409-417. doi:10.1037/a0025777

Gullone, E., Hughes, E. K., King, N. J., \& Tonge, B. (2009). The normative development of emotion regulation strategy use in children and adolescents: A 2-year follow-up study. Journal of Child Psychology and Psychiatry, 51, 567-674.

Hayward, C., Wilson, K. A., Lagle, K., Kraemer, H. C., Killen, J. D., \& Taylor, C. B. (2008). The developmental psychopathology of social anxiety in adolescents. Depression and Anxiety, 25(3), 200-206. https://doi.org/10.1002/da.20289

Hofmann, S. G., Gutner, C. A., \& Fang, A. (2012). Social Anxiety Disorder. Encyclopedia of Human Behavior, 450455. doi:10.1016/b978-0-12-375000-6.00330-x

Hudson, J. L., \& Rapee, R. M. (2000). "The Origins of Social Phobia," Behavior Modification, 24 (1) 102-130.

Jazaieri, H., Morrison, A. S., Goldin, P. R., \& Gross, J. J. (2015). The role of emotion and emotion regulation in social anxiety disorder. Current Psychiatry Reports, 17(1), 531.

Johnson, R. L., \& Glass, C. R. (1989). Heterosocial anxiety and direction of attention in high school boys. Cognitive Therapy and Research, 13, 509-526.

Kağıtçıbaşı, C. (1982). Old age security value of children and socioeconomic development: Cross-national evidence. Journal of Cross-Cultural Psychology, 13, 29-42.

Kalaycı, Ş. (2008). SPSS Uygulamalı çok Değişkenli İstatistik Teknikleri. Ankara: Asil Yayın Dağıtım Ltd.

Karasar, N. (2012). Bilimsel araştırma yöntemi. Ankara: Nobel Yayıncılık.

Kashdan, T. B., \& Breen, W. E. (2008). Social anxiety and positive emotions: A prospective examination of a self-regulatory model with tendencies to suppress or express emotions as a moderating variable. Behavior Therapy, 39, 1-12. doi:http://dx.doi.org/10.1016/j.beth.2007.02.003

Kelley, S. A., Brownell, C. A., \& Campbell, S. B. (2000). Mastery motivation and self-evaluative affect in toddlers: Longitudinal relations with maternal behavior. Child Development, 71, 1061-1071.

Kerr, M., Stattin, H., \& Özdemir, M. (2012). Perceived parenting style and adolescent adjustment: Revisiting directions of effects and the role of parental knowledge. Developmental Psychology, 48(6), 1540-1553. doi:10.1037/a0027720

Kessler, R. C. (2003). The impairments caused by social phobia in the general population: implications for intervention. Acta Psychiatrica Scandinavica, 108(s417), 19-27. doi:10.1034/j.1600-0447.108.s417.2.x 
Kessler, R. C., Berglund, P., Demler, O., Jin, R., Merikangas, K. R., \& Walters, E. E. (2005). Lifetime Prevalence and Age-of-Onset Distributions of DSM-IV Disorders in the National Comorbidity Survey Replication. Archives of General Psychiatry, 62(6), 593. doi:10.1001/archpsyc.62.6.593

Kessler, R. C., Petukhova, M., Sampson, N. A., Zaslavsky, A. M., \& Wittchen, H.-U. (2012). Twelve-month and lifetime prevalence and lifetime morbid risk of anxiety and mood disorders in the United States. International Journal of Methods in Psychiatric Research, 21(3), 169-184. doi:10.1002/mpr.135

Koydemir-Özden, S., \& Demir, A. (2009). The Relationship Between Perceived Parental Attitudes and Shyness among Turkish Youth: Fear of Negative Evaluation and Self-esteem as Mediators. Current Psychology, 28(3), 169-180. doi:10.1007/s12144-009-9054-1

Kring, A. M., \& Sloan, D. M. (Eds.). (2010). Emotion regulation and psychopathology: A transdiagnostic approach to etiology and treatment. The Guilford Press.

Koole, S. (2009). The psychology of emotion regulation: an integrative review. Cognition and Emotion, 23(1), 441.

La Greca, A. M., \& Lopez, N. (1998). Social anxiety among adolescents: Linkages with peer relations and friendships. Journal of Abnormal Child Psychology, 26(2), 83-94.

La Greca, A. M., Dandes, S. K., Wick, P., Shaw, K., \& Stone, W. L. (1988). Development of the Social Anxiety Scale for Children: Reliability and concurrent validity. Journal of Clinical Child Psychology, 17(1), 84-91.

Lapsley, D. K. (1993). Toward an integrated theory of adolescent ego development: The "new look" atadolescent egocentrism. American Journal of Orthopsychiatry, 63(4), 562-571.

Lee, F. S., Heimer, H., Giedd, J. N., Lein, E. S., Sestan, N., Weinberger, D. R., \& Casey, B. J. (2014). Adolescent mental health-opportunity and obligation. Science, 346, 547-549.

Lieb, R., Wittchen, H., Hofler, M., Fuetsch, M., Stein, M., \& Merikangas, K. (2000). Parental psychopathology, parenting styles, and the risk of social phobia in offspring: A prospective-longitudinal community study. Archives of General Psychiatry, 57, 859-866.

Maccoby, E. E., \& Martin, J. A. (1983). Socialization in the Context of the Family: 111 Parent - Child Interaction. P. H. Mussen ve E. M. Hetherington (Ed.), Handbook of Child Psychology: Socialization. Personality and Social Development. New York: Wiley

Maccoby, M. (1980). Work and human development. Professional Psychology, 11(3), 509-519.

Mash, E. J., \& Wolfe, D. A. (2002). Anxiety Disorders. Abnormal Child Psychology (2.Ed ). Belmant: Thomson Learning.

McLaughlin, K. A., Hatzenbuehler, M. L., \& Hilt, L. M. (2009). Emotion dysregulation as a mechanism linking peer victimization to internalizing symptoms in adolescents. Journal of Consulting and Clinical Psychology, 77, 894-904.

McLean, C. P., Miller, N. A., \& Hope, D. A. (2007). Mediating social anxiety and disordered eating: The role of expressive suppression. Eating Disorders, 15, 41-54. doi:10.1080/10640260601044485

Nolen-Hoeksema, S., \& Aldao, A. (2011). Gender and age differences in emotion regulation strategies and their relationship to depressive symptoms. Personality and Individual Differences, 51,704-708.

Perini, S. J., Abbott, M. J., \& Rapee, R. M. (2006). Perception of performance as a mediator in the relationship between social anxiety and negative post-event rumination. Cognitive Therapy \& Research, 30, 645-659. 
Phillips, K. F. V., \& Power, M. J. (2007). A new self-report measure of emotion regulation in adolescents: The Regulation of Emotions Questionnaire. Clinical Psychology EPsychotherapy, 14(2), 145-156. doi:10.1002/cpp.523

Power, M. J., \& Dalgleish, T. (1997). Cognition and emotion: From order to disorder. Hove: Psychology Press. Clinical Psychology \& Psychotherapy, 7(4), 340-340

Rapee, R. M. \& Spence, S. H. (2004). The etiology of social phobia: Empirical evidence and an initial model. Clinical Psychology Review, 24, 737-767.

Rork, K. E., \& Morris, T. L. (2009). Influence of parenting factors on childhood social anxiety: Direct observation of parental warmth and control. Child \& Family Behavior Therapy, 31(3), 220-235.

Rubin, K. H., Cheah, C. S. L., \& Fox, N. (2001). Emotion regulation, parenting, and display of social reticence in preschoolers. Early Education and Development, 1, 97-115.

Sackl-Pammer, P., Jahn, R., Özlü-Erkilic, Z., Pollak, E., Ohmann, S., Schwarzenberg, J., \& Akkaya-Kalayci, T. (2019). Social anxiety disorder and emotion regulation problems in adolescents. Child and Adolescent Psychiatry and Mental Health, 13(1). doi:10.1186/s13034-019-0297-9

Schafer, J. O., Naumann, E., Holmes, E. A., Tuschen-Caffier, B., \& Samson, A. C. (2017). Emotion regulation strategies in depressive and anxiety symptoms in youth: A meta-analytic review. Journal of Youth and Adolescence, 46, 261-276. doi:10.1007/s10964-016-0585-0

Schmidt, L. (2008). Social anxiety disorder: A review of environmental risk factors. Neuropsychiatric Disease and Treatment, 123. doi:10.2147/ndt.s1799

Stein, M. B., \& Stein, D. J. (2008). Social anxiety disorder. The Lancet, 371(9618), 1115-1125. doi:10.1016/s01406736(08)60488-2

Stein. A., Woolley, H., Cooper, S., Winterbottom, J., Fairburn, C. G, \& Cortina-Borja, M. (2006) Eating habits and attitudes among 10-year-old children of mothers with eating disorders: longitudinal study. The British Journal of Psychiatry: The Journal of Mental Science, 189(4), 324-9.

Steinberg, L., Dornbusch, S. M., \& Brown, B. B. (1992). Ethnic differences in adolescent achievement: An ecological perspective. American Psychologist, 47,723-729. doi:10.1037/0003-066X.47.6.723

Sümer, N., \& Güngör, D. (1999). Çocuk yetiștirme stillerinin baglanma stilleri, benlik degerlendirmeleri ve yakın iliş̧kiler üzerindeki etkisi. Türk Psikoloji Dergisi, 14, 35-58.

Tabachnick, B. G., \& Fidell, L. S. (2007). Experimental Designs Using ANOVA. Belmont: Thomson/Brooks/Cole.

Takako, S. (1994). Familial and Developmental Antecedents of Social Anxiety. (unpublished Master's thesis). Temple Üniversitesi, Pennsylvania, US.

Teachman, B. A., \& Allen, J. P. (2007). Development of social anxiety: Social interaction predictors of implicit and explicit fear of negative evaluation. Journal of Abnormal Child Psychology, 35(1), 63-78.

Theall-Honey, L. A., \& Schmidt, L. A (2006) Do temperamentally shy children process emotion diferently than nonshy children? Behavioral, psychophysiological, and gender diferences in reticent preschoolers. Developmental Psychobiology, 48, 187-196.

Tsui, T. Y. L., Lahat, A. \& Schmidt, L. A. (2016). Linking Temperamental Shyness and Social Anxiety in Childhood and Adolescence: Moderating Influences of Sex and Age. Child Psychiatry \& Human Development, 48(5), 778-785. doi:10.1007/s10578-016-0702-z 
Turk, C. L, Heimberg, R. G, Luterek, J. A, Mennin, D. S., \& Fresco, D. M. (2005). Emotion Dysregulation in Generalized Anxiety Disorder: A Comparison with Social Anxiety Disorder. Cognitive Therapy and Research, 29(1), 89-106.

Türkçapar, H. (1999). Sosyal Fobinin Psikolojik Kuramı. Klinik Psikiyatri, 28, 452-456.

Van der Bruggen, C. O., Stams, G. J. J. M. \& Bögels, S. M. (2008). Research Review: The relation between child and parent anxiety and parental control: a meta-analytic review. Journal of Child Psychology and Psychiatry, 49(12), 1257-1269.

Weiss, B., Dodge, K. A., Bates, J. E., \& Pettit, G. S. (1992). Some consequences of early harsh discipline: Child aggression and maladaptive social information processing style. Child Development, 63, 1321-1335.

Wong, Q. J., \& Rapee, R. M. (2016). The aetiology and maintenance of social anxiety disorder: A synthesis of complementary theoretical models and formulation of a new integrated model. Journal of Affective Disorders, 203, 84-100.

Woodruff-Borden, J., Morrow, C., Bourland, S., \& Cambron, S. (2002). The behavior of anxious parents: Examining mechanisms of transmissions of anxious from parent to child. Journal of Clinical Child and Adolescent Psychology, 31, 364-374.

Yörükoğlu, A. (1992). Çocuk Ruh Sağlığı, Özgür Yayın Dağıtım, 17.bsk., İstanbul.

Young, K., Sandman, C., \& Craske, M. (2019). Positive and Negative Emotion Regulation in Adolescence: Links to Anxiety and Depression. Brain Sciences, 9(4), 76. doi:10.3390/brainsci9040076

Zimmermann, P., \& Iwanski, A. (2014). Emotion regulation from early adolescence to emerging adulthood and middle adulthood: Age differences, gender differences, and emotion-specific developmental variations. International Journal of Behavioral Development, 38(2), 182-194. 